\title{
Promoter hypermethylation of the p16 and Wif-1 genes as an independent prognostic marker in stage IA non-small cell lung cancers
}

\author{
MITSURU YOSHINO, MAKOTO SUZUKI, LEI TIAN, YASUMITSU MORIYA, HIDEHISA HOSHINO, \\ TATSURO OKAMOTO, SHIGETOSHI YOSHIDA, KIYOSHI SHIBUYA and ICHIRO YOSHINO
}

Department of Thoracic Surgery, Graduate School of Medicine, Chiba University, 1-8-1 Inohana, Chuoh-ku, Chiba 260-8677, Japan

Received June 4, 2009; Accepted August 7, 2009

DOI: 10.3892/ijo_00000437

\begin{abstract}
Hypermethylation of promoter $\mathrm{CpG}$ islands is a major inactivation mechanism of tumor suppressor genes, some of which are thought to be related to the prognosis of patients with non-small cell lung cancer (NSCLC). Therefore, hypermethylation of the specific genes may be expected to serve as a prognostic biomarker for NSCLC. In this study, the methylation status of 14 genes was analyzed in 44 stage IA NSCLC cases using methylation-specific PCR. Hypermethylation was detected in PTGER2 (70\% of cases), DRM/Gremlin (66\%), sFRP-2 (57\%), IL-12Rß2 (48\%), Reprimo (41\%), APC (39\%), CXCL12 (39\%), HPPl (30\%), SPARC (30\%), sFRP-5 (30\%), p16 (25\%), RUNX3 (20\%), sFRP-1 (20\%) and Wif-1 (16\%). Patients with p16, sFRP-5, Wif-1 or CXCL12 methylation had a significantly shorter duration of relapse-free survival than their counterparts with an unmethylated gene $(p 16, \mathrm{P}=0.011 ; s F R P-5, \mathrm{P}=0.030$, Wif- 1 , $\mathrm{P}=0.036 ; C X C L 12, \mathrm{P}=0.026)$. Also, those with methylated HPP 1, p16 or Wif-1 had a significantly shorter duration of overall survival $(H P P 1, \mathrm{P}=0.031 ; p 16, \mathrm{P}=0.026$; Wif- 1 , $\mathrm{P}=0.008)$. Multivariate analysis revealed that $p 16$ methylation in relapse-free survival and Wif-1 methylation in overall survival were the strongest independent prognostic factors ( $p 16, \mathrm{P}=0.036$; Wif- $1, \mathrm{P}=0.035)$. In conclusion, the hypermethylation of the p16 and Wif-1 genes has potential as biomarkers that may be used to predict the prognosis of stage IA NSCLC.
\end{abstract}

\section{Introduction}

Lung cancer is the most frequent cause of cancer-related death in the world (1). Despite advances in the detection and

Correspondence to: Dr Makoto Suzuki, Department of Thoracic Surgery, Graduate School of Medicine, Chiba University, 1-8-1 Inohana, Chuoh-ku, Chiba 260-8677, Japan

E-mail: smakoto@faculty.chiba-u.jp

Key words: non-small cell lung cancer, methylation, recurrence, prognosis, biomarker, stage IA treatment of lung cancer, the overall 5-year survival rate remains approximately $15 \%$ (2). The tumor, lymph node, metastasis (TNM) staging system for lung cancer is widely used as a guide for predicting prognoses $(3,4)$. However, this system makes it difficult to accurately determine the prognosis for each patient, since recurrence is not uncommon even in surgically resected early-stage disease.

Alterations in DNA methylation patterns are the earliest and most common events during the process of tumorigenesis. Promoter region methylation of certain genes results in down-regulation of transcriptional activity through local effects on DNA-binding proteins and alterations of chromatin structure. Hypermethylation of tumor suppressor genes (TSGs) has been reported in a wide spectrum of human cancers (5-7), and it may be the most common mechanism of inactivating TSGs in lung cancer. Hypermethylation of several genes has been correlated with malignant potential in non-small cell lung cancer (NSCLC) $(8,9)$ : FHIT (associated with poor survival) (10), pl6 and/or RASSF1A (11), DH1 (12), co-hypermethylation of p16 and FHIT (2), and p16 and CDH13 (correlated with recurrence) (13). These findings suggest that hypermethylation of specific genes may serve as biomarkers to predict prognosis after complete resection of NSCLC. In addition, hypermethylation is a potentially reversible epigenetic change; accordingly, it has recently become a target for gene therapy (14).

Postoperative adjuvant chemotherapy has been established as a standard course of treatment in certain operable cases of NSCLC. However, rather than improving survival in stage IA, there is evidence that adjuvant chemotherapy may be harmful $(15,16)$. On the other hand, there are some patients who suffer from recurrence even if stage IA NSCLC. If patients who are likely to suffer from recurrence could be identified at diagnosis, then a tailor-made strategy may be instituted.

In this study, we determined the methylation status of 14 cancer-related genes (HPP1, DRM/Gremlin, RUNX3, p16, Reprimo, IL-12Rß2, SPARC, sFRP-1, sFRP-2, sFRP-5, Wif-1, $A P C, C X C L 12$ and PTGER2) in patients with stage IA NSCLC. We also investigated the relationship between the methylation status of these genes and the mutation profiles of the EGFR and KRAS mutations. 
Table I. Clinicopathological features of stage IA NSCLC patients.

\begin{tabular}{|c|c|c|c|c|c|}
\hline Variables & No. of patients & $\begin{array}{c}\text { Relapse-free } \\
\text { 5-year survival }(\%)\end{array}$ & P-value & $\begin{array}{c}\text { Overall } \\
\text { 5-year survival }(\%)\end{array}$ & P-value \\
\hline \multicolumn{6}{|l|}{ Gender } \\
\hline M & 22 & 86 & 0.6 & 90 & 0.6 \\
\hline $\mathrm{F}$ & 22 & 81 & & 85 & \\
\hline \multicolumn{6}{|l|}{$\mathrm{Age}^{\mathrm{a}}$} \\
\hline$<63$ & 21 & 81 & 0.8 & 90 & 0.9 \\
\hline$\geq 63$ & 23 & 85 & & 85 & \\
\hline \multicolumn{6}{|l|}{ Histology } \\
\hline Adenocarcinoma & 30 & 82 & $0.8^{\mathrm{b}}$ & 89 & $0.4^{\mathrm{b}}$ \\
\hline Squamous cell carcinoma & 11 & 82 & & 81 & \\
\hline Large-cell carcinoma & 3 & 100 & & 100 & \\
\hline \multicolumn{6}{|l|}{ p-factor } \\
\hline p0 & 28 & 86 & 0.4 & 89 & 0.3 \\
\hline $\mathrm{p} 1$ & 16 & 76 & & 84 & \\
\hline \multicolumn{6}{|l|}{ Tumor size } \\
\hline$\leq 2 \mathrm{~cm}$ & 14 & 86 & 0.4 & 93 & 0.6 \\
\hline$>2 \mathrm{~cm}$ & 30 & 82 & & 84 & \\
\hline \multicolumn{6}{|l|}{ Smoking } \\
\hline Never & 21 & 80 & $>0.9$ & 89 & 0.5 \\
\hline Smoker & 23 & 87 & & 86 & \\
\hline
\end{tabular}

aDivided into 2 groups by median age. ${ }^{\mathrm{b}}$ Adenocarcinoma vs. squamous cell carcinoma.

\section{Materials and methods}

Patients and clinical samples. A total of 44 NSCLCs and 32 corresponding normal lung tissue specimens from the same patients were surgically resected and histologically diagnosed as stage IA NSCLC at the Chiba University Hospital, Japan. Institutional Review Board approval and written informed consent from all participants were obtained. Tissue samples were immediately frozen and stored at $-80^{\circ} \mathrm{C}$ until analysis. The patients had neither undergone any chemotherapy or radiotherapy prior to surgical resection, nor adjuvant chemotherapy or radiotherapy after resection.

The patients included 22 males and 22 females who ranged in age from 44 to 90 years (average, 63.2 years) at the time of diagnosis. TNM staging was based on the TNM classification system of the International Union Against Cancer (UICC) (17). The histological subtypes included 30 adenocarcinomas, 11 squamous cell carcinomas and 3 large-cell carcinomas (18). Twenty-three patients were smokers (including both current and former smokers), and 21 patients had never smoked. Follow-up evaluations, offered to all patients, ranged from 16.0 to 147.2 months after surgery (median, 77.4 months).

DNA extraction and methylation-specific PCR. Genomic DNA was obtained from primary tumors and normal cells by digestion with Proteinase K (Life Technologies, Carlsbad, CA, USA) followed by phenol/chloroform (1:1) extraction.
DNA methylation patterns in the $\mathrm{CpG}$ island of 14 tumorrelated genes were determined using methylation-specific PCR (MSP) as described previously (19-24). These genes were chosen based on reports that their expression is downregulated by hypermethylation in lung cancer (19-23).

Briefly, $1 \mu \mathrm{g}$ of genomic DNA was denatured with $\mathrm{NaOH}$ and modified with bisulfite. The modified DNA was purified with a Wizard DNA Purification Kit (Promega, Madison, WI, USA), desulfonated with $\mathrm{NaOH}$, precipitated with ethanol, and resuspended in water. PCR amplification was performed with bisulfite-treated DNA as a template using specific primer sequences for the methylated and unmethylated forms of the gene. CpGenome Universal Methylated Control DNA (Chemicon International, Inc., Temecula, CA, USA) and DNA from the blood of healthy individuals were treated with bisulfite as described above and used as methylated and unmethylated controls. Water blanks were included with each assay. PCR products were visualized on $2 \%$ agarose gels stained with ethidium bromide. The results were confirmed by repeating the bisulfate treatment and MSP for all samples.

Mutation assay. Sequences of the first 4 exons (18-21) of the EGFR tyrosine kinase domains and exon 2 of KRAS were analyzed as described previously (25). All PCR products were incubated using exonuclease I and shrimp alkaline phosphatase (Amersham Biosciences, Piscataway, NJ, USA) and sequenced using Applied Biosystems PRISM dye- 


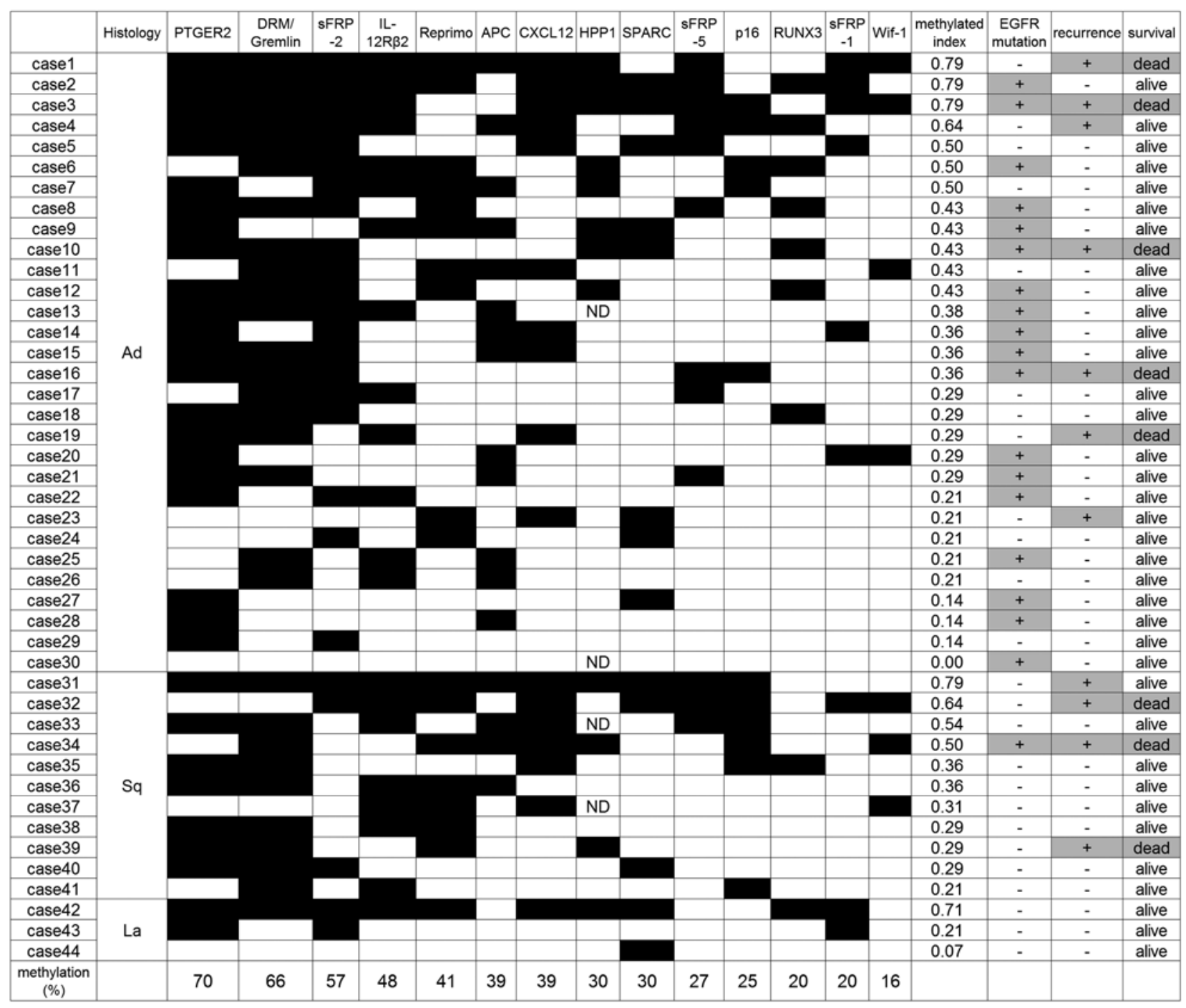

Figure 1. Clustering analysis indicates a correlation between methylation status, methylation index, EGFR mutations, recurrence, and survival for all cases. At least one of the 14 evaluated genes was hypermethylated in 43/44 cases (97.7\%). The numerical value of the lower line expresses a positive rate for each genetic methylation. ND, not done; solid box, methylated band detected; open box, unmethylated band detected; Ad, adenocarcinoma; Sq, squamous cell carcinoma; La, large-cell carcinoma.

terminator cycle sequencing (Applied Biosystems, Foster City, CA, USA). All sequence variants were confirmed by independent PCR amplifications and sequencing in both directions.

Statistical analysis. Statistical differences between groups were examined using the Fisher's exact test, Chi-square test, and Mann-Whitney test. Relapse-free and overall survival times were calculated from the date of surgery until recurrence and death, or from the date of the last follow-up (censored). Survival was analyzed using Kaplan-Meier survival analysis, and comparisons between two groups were performed using the log-rank test. For multivariate analysis, independent prognostic factors were assessed using the Cox proportional hazards model. A P-value $<0.05$ was considered statistically significant.

The methylation index for each case was calculated as Total number of genes methylated/Total number of genes analyzed.

\section{Results}

Patient profiles. The clinicopathological features of the patients are described in Table I. Relapse-free and overall 5-year survival rates of all patients were 83.2 and $87.5 \%$, respectively. There was no significant association between survival and clinical features such as gender, age, histology, p-factor, tumor size and smoking.

Correlation between methylation status and clinicopathological factors. Profiles of the methylation status and the EGFR mutation are shown in Fig. 1. Hypermethylation of each gene was observed in $16-70 \%$ of cancerous tissues, but in $<6 \%(n=2)$ of non-neoplastic lung tissue. Thus, each gene methylation was a tumor-specific event $(\mathrm{P}<0.001)$.

The relationship between gene methylation status and clinicopathological features such as age, gender, histology, p-factor (p0 vs. p1), tumor size ( $\leq 2 \mathrm{vs.}>2 \mathrm{~cm}$ ), smoking history (never vs. smoker) was investigated (Table II). Elderly 


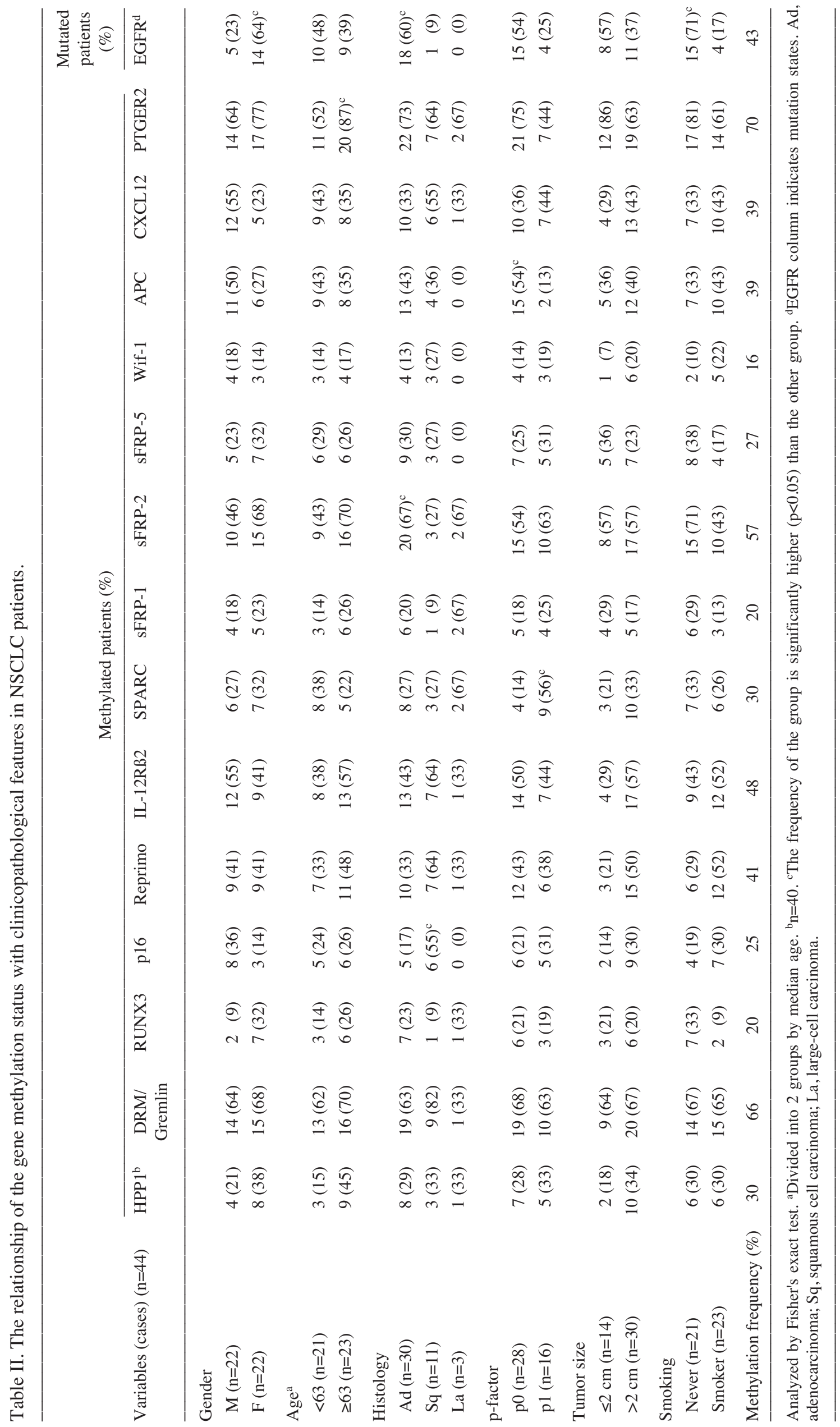



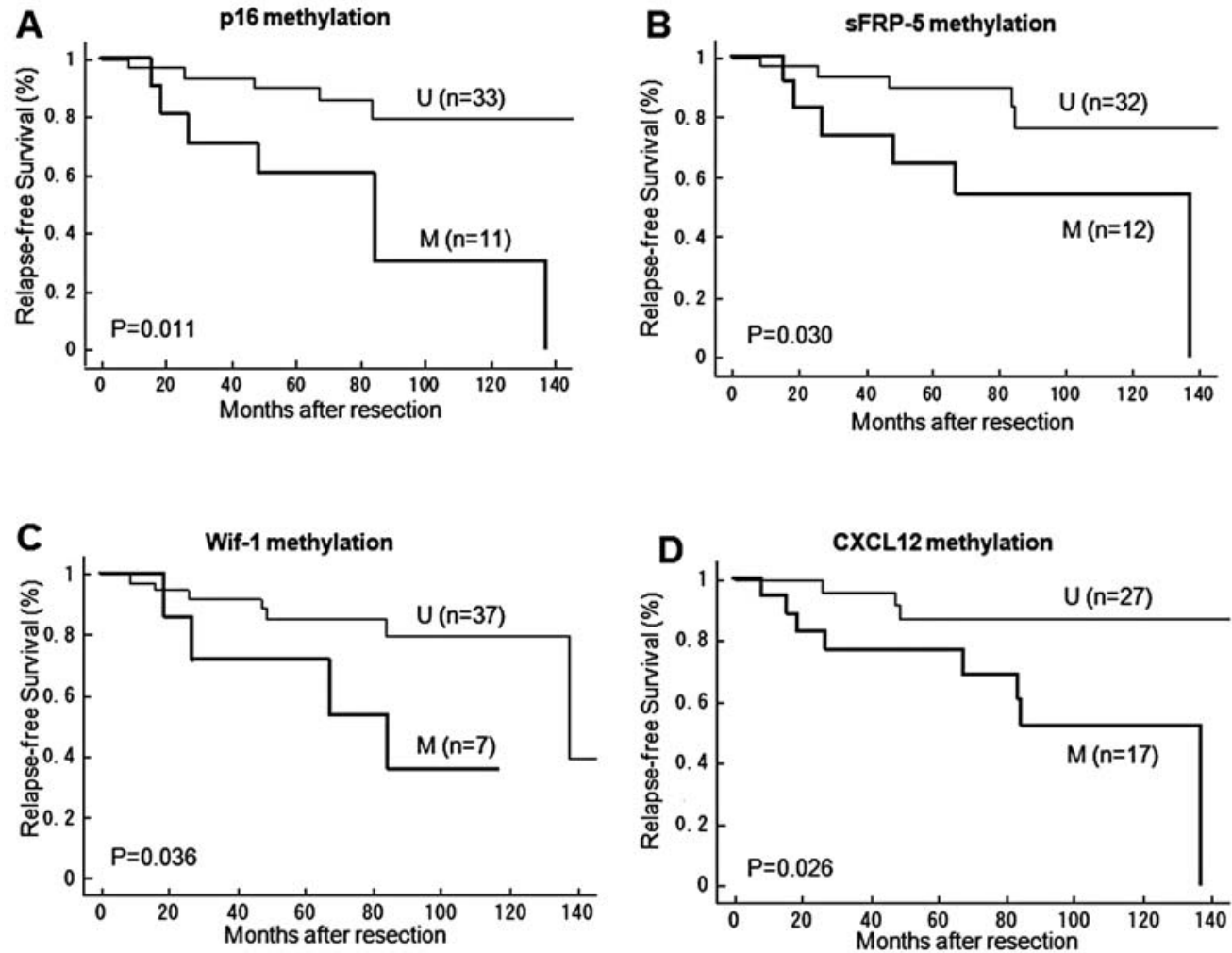

Figure 2. Correlation between the methylation status of p16 (A), sFRP-5 (B), Wif-1 (C), CXCL12 (D) and relapse-free survival of 44 NSCLC patients using the Kaplan-Meier method to generate survival curves. U, unmethylated cases; M, methylated cases. $\mathrm{P}=0.011(\mathrm{~A}), \mathrm{P}=0.030(\mathrm{~B}), \mathrm{P}=0.036(\mathrm{C})$ and $\mathrm{P}=0.026(\mathrm{D})$; log-rank test.

patients exhibited significantly more hypermethylation of PTGER2 (<63 years, 52\% (11/21) vs. $\geq 63$ years, $87 \%$ (20/23); $\mathrm{P}=0.02)$. p16 hypermethylation was more frequently observed in squamous cell carcinoma $(\mathrm{Sq})(\mathrm{Sq}, 55 \%(6 / 11)$ vs. Ad, $17 \%$ (5/30); $\mathrm{P}=0.041)$. In contrast, hypermethylation of $s F R P-2$ was more frequently observed in adenocarcinoma (Ad) (Ad, 67\% (20/30) vs. Sq, 27\% (3/11); $\mathrm{P}=0.036)$. In pleural invasion, SPARC methylation was more prevalent in p1 cases (p0, 14\% (4/28) vs. p1, 56\% (9/16); P=0.006), and $A P C$ methylation was found in more p0 cases (p0, 54\% $(15 / 28)$ vs. p1, $13 \%(2 / 16) ; \mathrm{P}=0.010)$.

Mutation state of NSCLC and its correlation with methylation and prognosis. We examined the sequences of KRAS and EGFR tyrosine kinase domains of 44 stage IA NSCLCs (Table II). Nineteen patients (43\%) had EGFR mutations, but the KRAS mutation could not be found in all cases. The frequency of the EGFR mutation was significantly higher among women (female, 64\% (14/22) vs. male, 23\% (5/22); $\mathrm{P}=0.014)$ and never-smokers (never-smoker, $71 \%(15 / 21)$ vs. smoker, $17 \%$ (4/23); $\mathrm{P}=0.001)$. The EGFR mutation was noted in 18 adenocarcinomas and one squamous cell carcinoma. There was no significant correlation between the presence of the EGFR mutation and hypermethylation of the 14 cancerrelated genes (Fig. 1), and the methylation index and EGFR mutation were not connected in adenocarcinoma.

Association of methylation status and prognosis. We examined the correlation between methylation and relapse-free or overall survival using Kaplan-Meier survival curves and the
Cox proportional hazards model. Fig. 2 shows the curves, and the results of the log-rank tests are listed in Table III. Patients who had 16 , sFRP-5, Wif- 1 or CXCL12 methylation in their tissues were found to have a significantly shorter duration of relapse-free survival than patients with a negative methylation status for each gene $(p 16, \mathrm{P}=0.011 ; s F R P-5$, $\mathrm{P}=0.030 ;$ Wif- $1, \mathrm{P}=0.036 ;$ CXCL12, $\mathrm{P}=0.026)$. Methylation status of the remaining genes had no correlation with relapsefree survival. In addition, patients with methylated $H P P 1$, p16 or Wif-1 had a significantly shorter duration of overall survival compared to patients with negative methylation status (HPP1, $\mathrm{P}=0.031 ; p 16, \mathrm{P}=0.026$; Wif $-1, \mathrm{P}=0.008$ ) (Table III, Fig. 3). Methylation status of the remaining genes did not correlate with overall survival.

Although the number of cases was small, we analyzed the survival of each case with adenocarcinoma or squamous cell carcinoma. Cases with p16 methylation had a shorter duration of relapse-free and overall survival in adenocarcinoma $(\mathrm{P}=0.003, \mathrm{P}=0.004$ respectively), while those with $s F R P-1$ methylation had a shorter overall survival in squamous cell carcinoma $(\mathrm{P}=0.002)$. There were no significant survival differences noted between the remaining 11 genes in the comparison of methylation-positive and methylation-negative tumors tested in histology (Fig. 4).

The Cox proportional hazards model was used to determine if the association between gene methylation and relapse-free or overall survival remained after adjusting for covariates of age, gender, tumor size and histology (Tables IV and V). A multivariate analysis revealed that the presence of hypermethylated $p 16, s F R P-5$, Wif- 1 or CXCL12 was an 
Table III. Correlation between gene methylation and relapse-free and overall survival by log-rank test.

\begin{tabular}{|c|c|c|c|c|c|c|}
\hline \multirow[b]{2}{*}{ Gene } & \multicolumn{2}{|c|}{ Relapse-free 5-year survival rate (\%) } & \multirow[b]{2}{*}{ P-value } & \multicolumn{2}{|c|}{ Overall 5-year survival rate (\%) } & \multirow[b]{2}{*}{ P-value } \\
\hline & Methylated & Unmethylated & & Methylated & Unmethylated & \\
\hline$H P P 1^{a}$ & 72.7 & 85.1 & 0.069 & 72.7 & 92.3 & $0.031^{\mathrm{b}}$ \\
\hline DRM/Gremlin & 78.6 & 92.9 & $0 ., 233$ & 84.9 & 92.9 & 0.181 \\
\hline RUNX3 & 77.8 & 84.7 & 0.917 & 87.5 & 87.7 & 0.583 \\
\hline p16 & 60.6 & 90.4 & $0.011^{\mathrm{b}}$ & 77.8 & 90.1 & $0.026^{\mathrm{b}}$ \\
\hline Reprimo & 88.2 & 80.0 & 0.447 & 87.8 & 87.3 & 0.687 \\
\hline IL-12RB2 & 80.1 & 86.5 & 0.323 & 83.3 & 90.9 & 0.463 \\
\hline SPARC & 76.2 & 86.3 & 0.464 & 76.2 & 92.7 & 0.633 \\
\hline sFRP-1 & 77.8 & 84.5 & 0.523 & 77.8 & 90.1 & 0.257 \\
\hline sFRP-2 & 78.7 & 89.5 & 0.591 & 86.4 & 88.8 & 0.664 \\
\hline sFRP-5 & 64.8 & 90.0 & $0.030^{\mathrm{b}}$ & 80.0 & 89.7 & 0.077 \\
\hline Wif-1 & 71.4 & 85.6 & $0.036^{\mathrm{b}}$ & 71.4 & 90.8 & $0.008^{\mathrm{b}}$ \\
\hline APC & 94.1 & 75.9 & 0.552 & 100.0 & 79.8 & 0.261 \\
\hline CXCL12 & 76.5 & 87.3 & $0.026^{\mathrm{b}}$ & 81.3 & 91.3 & 0.172 \\
\hline PTGER2 & 79.6 & 91.7 & 0.709 & 85.7 & 91.7 & 0.735 \\
\hline
\end{tabular}

$\mathrm{CI}$, confidence interval. ${ }^{\mathrm{a}} \mathrm{n}=40$. ${ }^{\mathrm{b}}$ Statistically significant.
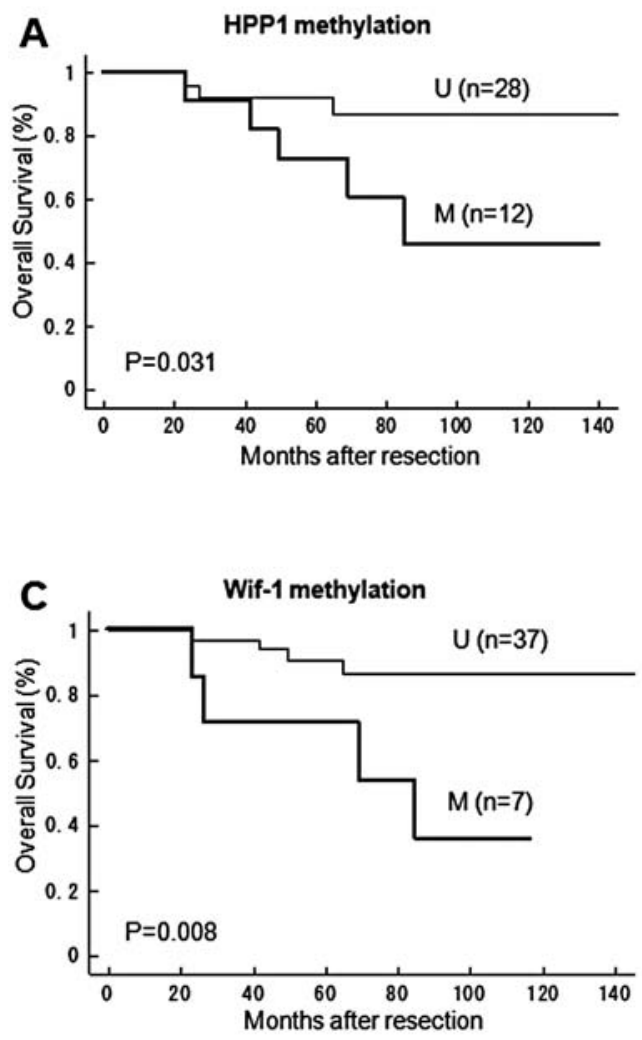

independent prognostic factor in relapse-free survival $(p 16$, $\mathrm{P}=0.004 ; s F R P-5, \mathrm{P}=0.014 ;$ Wif $-1, \mathrm{P}=0.045 ;$ CXCL12, $\mathrm{P}=0.025$ ) (Table IVA). Multivariate analysis of these four genes was performed to assess which methylation is strongly related to convalescence, and p16 methylation was revealed as the strongest prognostic factor for recurrence (Table VA). Likewise, an examination of overall survival showed that

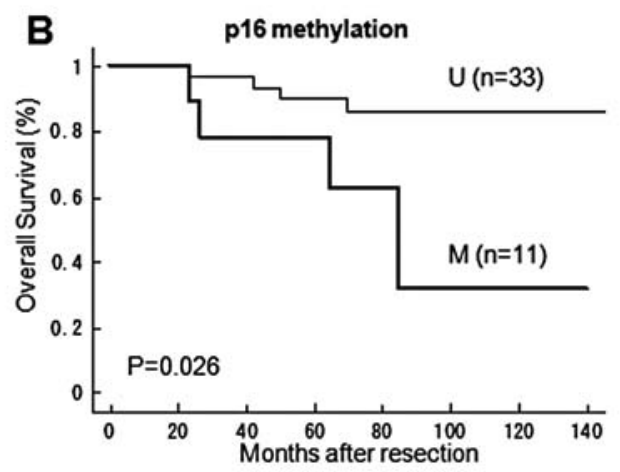

Figure 3. Correlation between the methylation status of HPP1 (A), p16 (B), Wif-1 (C) and overall survival of 44 NSCLC patients using the Kaplan-Meier method to generate survival curves. U, unmethylated cases; M, methylated cases. $\mathrm{P}=0.031$ (A), $\mathrm{P}=0.026$ (B) and $\mathrm{P}=0.008$ (C); log-rank test. methylation of $p 16$ or Wif- 1 is an independent prognostic factor ( $p 16, \mathrm{P}=0.021$; Wif- $1, \mathrm{P}=0.014)$ (Table IVB). Further multivariate analysis of these two genes revealed that Wif-1 methylation was the only strong prognostic factor in overall survival (Table VB), and that the methylation index was significantly related in both relapse-free survival and overall survival. 

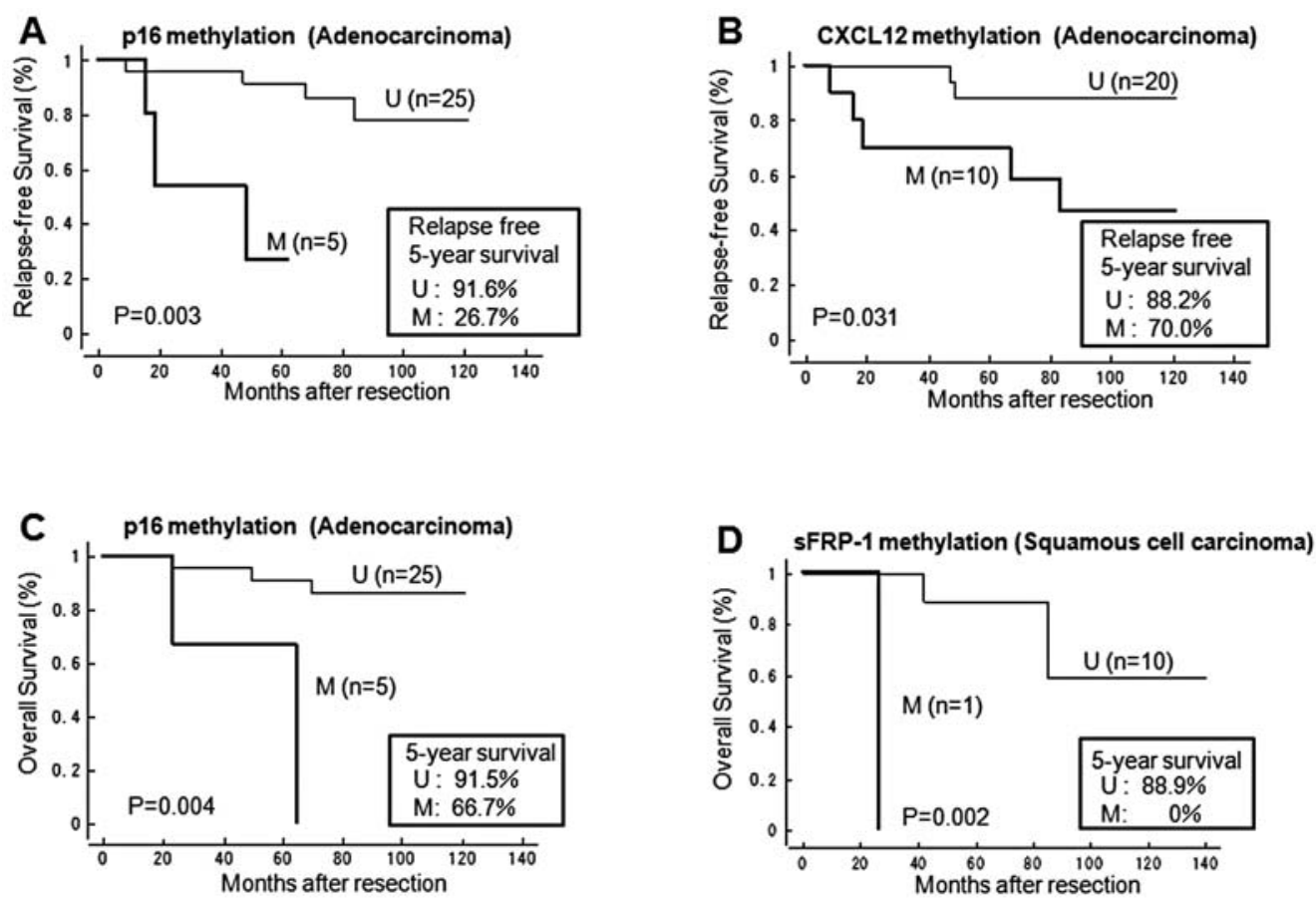

Figure 4. Kaplan-Meier curves of relapse-free survival for 30 patients with adenocarcinoma (A and B), overall survival for 30 patients with adenocarcinoma (C) and 11 patients with squamous cell carcinoma (D). A, Correlation between the methylation status of p16 and relapse-free survival of 30 adenocarcinoma patients $(\mathrm{P}=0.001, \log$-rank test). $\mathrm{B}$, Correlation between the methylation status of $C X C L 12$ and relapse-free survival of 30 adenocarcinoma patients $(\mathrm{P}=0.03)$. $\mathrm{C}$, Correlation between the methylation status of $p 16$ and overall survival of 30 adenocarcinoma patients $(\mathrm{P}=0.004)$. $\mathrm{D}$, Correlation between the methylation status of $s F R P-1$ and overall survival of 11 squamous cell carcinoma patients $(\mathrm{P}=0.002)$. $\mathrm{U}$, unmethylated cases; M, methylated cases .

\section{Discussion}

The prognosis of patients with NSCLC remains poor because of early recurrence and metastasis after complete surgical resection. Therefore, it is necessary to examine the groups with poor prognoses in order to perform effective post-surgical treatment. We examined the methylation frequency of 14 genes to identify biomarkers to predict the prognosis of patients with stage IA NSCLC after surgery, and found possible predictive genes.

The p16 gene is a TSG located on 9p21 chromosome that encodes a cyclin-dependent kinase, a key protein regulator of progression through the $\mathrm{G} 1$ phase of the cell cycle. The $p 16$ protein plays an important role in the binding and inhibition of cyclin D kinase activity and in regulating phosphorylation of the retinoblastoma protein $(\mathrm{p} 105 \mathrm{Rb})(26)$. Epigenetic alterations, such as methylation of $\mathrm{CpG}$ islands in the promoter regions of TSGs, are reportedly frequent events in lung cancer development (27). Frequent inactivation of $p 16$ by methylation in diverse cancers was reported in 1995. This methylation imposed a loss of p16 transcriptional expression that was reversible after treatment with 5-deoxyazacytidine $(28,29)$. After these findings, other studies showed that the $p 16$ promoter region was methylated in lung cancer at frequencies between 20 to $70 \%(30,31)$. In this study, we found $p 16$ methylation in $25 \%$ of cases. In addition, when stratified by histological type, $p 16$ promoter methylation was significantly higher in squamous cell carcinoma $(55 \%)$ than in adenocarcinoma (15\%) (Fisher's exact test, $\mathrm{P}=0.016)(32)$. This high prevalence of $p 16$ promoter methylation in squamous cell carcinoma is probably related to a smoking habit, which is considered a risk factor for squamous cell carcinoma development. Several authors have described a significant association between smoking and the methylation of some genes $(33,34)$, but in our study we found that $p 16$ promoter methylation was independent of a smoking habit, maybe due to the small number of samples. In addition, p16 methylation was thought to be correlated with pulmonary metastasis in this study (data not shown).

Members of the Wnt pathway play a critical role in human carcinogenesis. Wnt antagonists were recently identified, and their role in carcinogenesis is gradually being unveiled. Wnt antagonists can be divided into two groups according to their functional mechanisms. The first group includes the secreted frizzled-related protein $(s F R P)$ family, Wnt inhibitory factor1 (Wif-1) and Cerberus. They inhibit Wnt signaling by direct binding to Wnt molecules. The second group, including the Dickkof $(D K K)$ family, inhibits Wnt signaling by binding to the LRP5/LRP6 component of the Wnt receptor complex (35). Wif- 1 is a highly conserved gene that was first identified in the human retina. Wif- 1 is a secreted antagonist that can bind Wnt in the extracellular space and inhibit Wnt signaling. Recently, down-regulation of Wif- 1 has been reported in several types of human cancers and has been confirmed by immunohistochemistry in $60 \%$ of breast cancers and $75 \%$ of lung cancers. Mazieres et al (36) reported that Wif- 1 silencing correlates with hypermethylation of its promoter in both cancer cell lines and human NSCLC primary tissues. In our study, Wif-1 hypermethylation was strongly correlated with poor prognosis. Thus, silencing of Wif- 1 may increase the malignant potential of NSCLC.

Hypermethylation of the SPARC, PTGER2 and p16 genes has been related to the EGFR mutation $(24,25)$. However, we could not find a correlation between the EGFR mutation and 
Table IV. Results of multivariate analysis using the Cox proportional hazards model of prognostic factors for relapsefree and overall survival.

A, Relapse-free survival

\begin{tabular}{|c|c|c|c|}
\hline \multirow{2}{*}{$\begin{array}{l}\text { Variable } \\
\text { HPP1 methylation }\end{array}$} & \multicolumn{2}{|c|}{ Hazards ratio $(95 \% \mathrm{CI})$} & \multirow{2}{*}{$\begin{array}{c}\text { P-value } \\
0.058\end{array}$} \\
\hline & 3.743 & $(0.956-14.656)$ & \\
\hline DRM/Gremlin methylation & 2.773 & $(0.557-13.789)$ & 0.213 \\
\hline RUNX3 methylation & 0.806 & $(0.140-4.638)$ & 0.810 \\
\hline p16 methylation & 8.158 & $(1.920-34.650)$ & $0.004^{\mathrm{a}}$ \\
\hline Reprimo methylation & 1.470 & $(0.414-5.219)$ & 0.551 \\
\hline IL-12Rß2 methylation & 1.756 & $(0.478-6.451)$ & 0.396 \\
\hline SPARC methylation & 1.423 & $(0.364-5.559)$ & 0.612 \\
\hline sFRP-1 methylation & 2.128 & $(0.479-9.451)$ & 0.321 \\
\hline sFRP-2 methylation & 2.056 & $(0.433-9.751)$ & 0.364 \\
\hline sFRP-5 methylation & 5.945 & $(1.431-24.705)$ & $0.014^{\mathrm{a}}$ \\
\hline Wif-1 methylation & 3.944 & $(1.033-15.057)$ & $0.045^{\mathrm{a}}$ \\
\hline APC methylation & 0.748 & $(0.187-2.992)$ & 0.681 \\
\hline CXCL12 methylation & 5.067 & $(1.230-20.877)$ & $0.025^{\mathrm{a}}$ \\
\hline PTGER2 methylation & 2.959 & $(0.491-17.834)$ & 0.237 \\
\hline Methylation index & 58.886 & $(2.572-1348.426)$ & $0.011^{\mathrm{a}}$ \\
\hline
\end{tabular}

B, Overall survival

\begin{tabular}{lcll}
\hline Variable & \multicolumn{2}{c}{ Hazards ratio (95\% CI) } & P-value \\
\hline HPP1 methylation & 4.651 & $(0.947-22.727)$ & 0.058 \\
DRM/Gremlin methylation & 3.678 & $(0.440-30.766)$ & 0.230 \\
RUNX3 methylation & 0.355 & $(0.036-3.476)$ & 0.373 \\
p16 methylation & 6.579 & $(1.326-32.258)$ & $0.021^{\mathrm{a}}$ \\
Reprimo methylation & 1.016 & $(0.223-4.637)$ & 0.983 \\
IL-12Rß2 methylation & 1.456 & $(0.317-6.693)$ & 0.630 \\
SPARC methylation & 1.143 & $(0.245-5.329)$ & 0.865 \\
sFRP-1 methylation & 2.767 & $(0.553-13.837)$ & 0.215 \\
sFRP-2 methylation & 1.756 & $(0.325-9.471)$ & 0.513 \\
sFRP-5 methylation & 4.685 & $(0.988-22.220)$ & 0.052 \\
Wif-1 methylation & 6.897 & $(1.473-32.258)$ & $0.014^{\mathrm{a}}$ \\
APC methylation & 0.476 & $(0.084-2.690)$ & 0.401 \\
CXCL12 methylation & 3.062 & $(0.642-14.598)$ & 0.160 \\
PTGER2 methylation & 2.331 & $(0.264-20.565)$ & 0.446 \\
Methylation index & 36.352 & $(1.118-1168.686)$ & $0.043^{\mathrm{a}}$ \\
\hline
\end{tabular}

Adjusted for age ( $<63$ vs. $\geq 63$ ), gender, tumor size $(\leq 2$ vs. $>2 \mathrm{~cm}$ ) and histology (adenocarcinoma vs. non-adenocarcinoma). CI, confidence

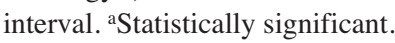

genetic methylation in 30 cases of stage IA adenocarcinoma. Again, this finding could have been the result of the small number of cases examined. Another explanation might be that the methylations which show a correlation with the EGFR mutation occur at stage II or higher.

In this study, we confirmed that the methylation status of four genes (p16, sFRP-5, Wif-1, CXCL12) is related to a prediction of recurrence, and only two of the four are
Table V. Results of multivariate analysis using the Cox proportional hazards model of prognostic factors for relapsefree and overall survival.

\begin{tabular}{|c|c|c|}
\hline Variable & Hazards ratio $(95 \% \mathrm{CI})$ & P-value \\
\hline Age $(<63$ vs. $\geq 63)$ & $2.627 \quad(0.532-12.963)$ & 0.236 \\
\hline Gender & $0.201 \quad(0.027-1.504)$ & 0.118 \\
\hline Tumor size $(\leq 2 \mathrm{vs} .>2 \mathrm{~cm})$ & $2.809 \quad(0.331-23.810)$ & 0.344 \\
\hline Histology (Adeno vs. non-Adeno) & $0.473(0.053-4.237)$ & 0.503 \\
\hline p16 methylation & $6.416 \quad(1.128-36.506)$ & $0.036^{\mathrm{a}}$ \\
\hline sFRP-5 methylation & $2.013 \quad(0.368-11.004)$ & 0.419 \\
\hline Wif-1 methylation & $1.480 \quad(0.307-7.133)$ & 0.625 \\
\hline CXCL12 methylation & $3.516 \quad(0.575-21.476)$ & 0.173 \\
\hline
\end{tabular}

B, Overall survival

\begin{tabular}{llll}
\hline Variable & \multicolumn{4}{c}{ Hazards ratio (95\% CI) } & P-value \\
\hline Age $(<63$ vs. $\geq 63)$ & 1.309 & $(0.245-7.008)$ & 0.753 \\
Gender & 0.157 & $(0.009-2.782)$ & 0.207 \\
Tumor size ( $\leq 2$ vs. $>2 \mathrm{~cm})$ & 1.563 & $(0.252-9.709)$ & 0.632 \\
Histology (Adeno vs. non-Adeno) & 0.696 & $(0.051-9.526)$ & 0.786 \\
p16 methylation & 5.435 & $(0.961-30.303)$ & 0.056 \\
Wif-1 methylation & 5.155 & $(1.125-23.810)$ & $0.035^{\text {a }}$
\end{tabular}

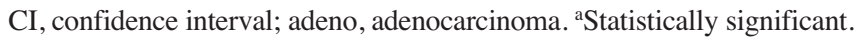

independent prognostic factors. Therefore, p16 and Wif-1 may be added to the list of prognostic markers in stage IA NSCLC. These findings could help improve the survival of stage IA NSCLC patients after complete resection in two ways. First, patients with these paticular methylations may be good candidates for adjuvant chemotherapy. Second, as these are methylation markers, demethylating agents might prove beneficial for such patients. It is well known that both carcinogenesis and tumor progression evolve from the genetic and epigenetic alterations of several genes. 5-Aza-2-deoxycitydine (5-AZA), an inhibitor of DNA methyltransferase can recover such epigenetic changes $(31,37)$. Therefore, if a drug that can selectively reverse epigenetic changes as well as hypermethylation is developed, a unique targeted strategy could emerge. Thus, although further study is needed to clarify the mechanism of these gene methylations, our results may contribute to an improvement in survival rates for specific stage IA NSCLC patients.

In conclusion, the methylation status of p16 and Wif-1 was found to be strongly associated with decreased survival in patients with stage IA NSCLC disease, a finding that reveals their potential as novel and unique prognostic factors for NSCLC.

\section{Acknowledgements}

This study was supported by a grant from the Smoking Research Foundation (M.S.). 


\section{References}

1. Greenlee RT, Hill-Harmon MB, Murray T and Thun M: Cancer statistics. CA Cancer J Clin 51: 15-36, 2001.

2. Kim JS, Kim JW, Han J, Shim YM, Park J and Kim DH: Cohypermethylation of $p 16$ and FHIT promoters as a prognostic factor of recurrence in surgically resected stage I non-small cell lung cancer. Cancer Res 66: 4049-4054, 2006.

3. Mountain CF: Revisions in the International System for Staging Lung Cancer. Chest 111: 1710-1717, 1997.

4. Naruke T, Tsuchiya R, Kondo H and Asamura H: Prognosis and survival after resection for bronchogenic carcinoma based on the 1997 TNM-staging classification: the Japanese experience. Ann Thorac Surg 71: 1759-1764, 2001.

5. Jones PA and Baylin SB: The fundamental role of epigenetic events in cancer. Nat Rev Genet 3: 415-428, 2002.

6. Esteller M, Corn PG, Baylin SB and Herman JG: A gene hypermethylation profile of human cancer. Cancer Res 61: 3225-3229, 2001.

7. Suzuki M, Sunaga N, Shames DS, Toyooka S, Gazdar AF and Minna JD: RNA interference-mediated knockdown of DNA methyltransferase 1 leads to promoter demethylation and gene re-expression in human lung and breast cancer cells. Cancer Res 64: 3137-3143, 2004.

8. Toyooka S, Toyooka KO, Maruyama R, et al: DNA methylation profiles of lung tumors. Mol Cancer Ther 1: 61-67, 2001

9. Zochbauer-Muller S, Minna JD and Gazdar AF: Aberrant DNA methylation in lung cancer: biological and clinical implications. Oncologist 7: 451-457, 2002.

10. Maruyama R, Sugio K, Yoshino I, Maehara Y and Gazdar AF: Hypermethylation of FHIT as a prognostic marker in non-small cell lung carcinoma. Cancer 100: 1472-1477, 2004.

11. Wang J, Lee JJ, Wang L, et al: Value of p16INK4a and RASSF1A promoter hypermethylation in prognosis of patients with resectable non-small cell lung cancer. Clin Cancer Res 10: 6119-6125, 2004.

12. Nakata S, Sugio K, Uramoto $\mathrm{H}$, et al: The methylation status and protein expression of $C D H 1, p 16(I N K 4 A)$, and fragile histidine triad in nonsmall cell lung carcinoma: epigenetic silencing, clinical features, and prognostic significance. Cancer 106: 2190-2199, 2006

13. Brock MV, Hooker CM, Ota-Machida E, et al: DNA methylation markers and early recurrence in stage I lung cancer. N Engl J Med 358: 1118-1128, 2008.

14. Slack A, Bovenzi V, Bigey $\mathrm{P}$, et al: Antisense $M B D 2$ gene therapy inhibits tumorigenesis. J Gene Med 4: 381-389, 2002.

15. Johnson BE and Rabin MS: Patient subsets benefiting from adjuvant therapy following surgical resection of non-small cell lung cancer. Clin Cancer Res 11: 5022s-5026s, 2005.

16. Tsuboi M, Ohira T, Saji H, et al: The present status of postoperative adjuvant chemotherapy for completely resected nonsmall cell lung cancer. Ann Thorac Cardiovasc Surg 13: 73-77, 2007.

17. Sobin LH and Wittekind C: TNM Classification of Malignant Tumours. Wiley-Liss, New York, 1997.

18. Travis WD, Brambilla E, Muller-Hermelink HK and Harris CC: Tumors of lung, pleura, thymus and heart. World Health Organization Classification of Tumors, 2004.

19. Suzuki M, Shigematsu H, Shames DS, et al: DNA methylationassociated inactivation of TGFß-related genes DRM/Gremlin, RUNX3, and HPP1 in human cancers. Br J Cancer 93: 1029-1037, 2005 .
20. Suzuki M, Shigematsu H, Takahashi T, et al: Aberrant methylation of Reprimo in lung cancer. Lung Cancer 47: 309-314, 2005.

21. Suzuki M, Iizasa T, Nakajima T, et al: Aberrant methylation of IL-12Rbeta2 gene in lung adenocarcinoma cells is associated with unfavorable prognosis. Ann Surg Oncol 14: 2636-2642, 2007.

22. Suzuki M, Hao C, Takahashi T, et al: Aberrant methylation of SPARC in human lung cancers. Br J Cancer 92: 942-948, 2005.

23. Suzuki M, Shigematsu H, Nakajima T, et al: Synchronous alterations of Wnt and epidermal growth factor receptor signaling pathways through aberrant methylation and mutation in non small cell lung cancer. Clin Cancer Res 13: 6087-6092, 2007.

24. Tian L, Suzuki M, Nakajima T, et al: Clinical significance of aberrant methylation of prostaglandin E receptor 2 (PTGER2) in nonsmall cell lung cancer. Cancer 113: 1396-1403, 2008.

25. Suzuki M, Shigematsu H, Iizasa T, et al: Exclusive mutation in epidermal growth factor receptor gene, HER-2, and KRAS, and synchronous methylation of nonsmall cell lung cancer. Cancer 106: 2200-2207, 2006

26. Wikenheiser-Brokamp KA: Retinoblastoma regulatory pathway in lung cancer. Curr Mol Med 6: 783-793, 2006.

27. Esteller $\mathrm{M}: \mathrm{CpG}$ island hypermethylation and tumour suppressor genes: a booming present, a brighter future. Oncogene 21: 5427-5440, 2002

28. Herman JG, Merlo A, Mao L, et al: Inactivation of the CDKN2/ p16/MTS1 gene is frequently associated with aberrant DNA methylation in all common human cancers. Cancer Res 55: 4525-4530, 1995

29. Merlo A, Herman JG, Mao L, et al: 5' CpG island methylation is associated with transcriptional silencing of the tumor suppressor p16/CDKN2/MTS1 in human cancers. Nat Med 1: 686-692, 1995.

30. Belinsky SA, Nikula KJ, Palmisano WA, et al: Aberrant methylation of p16 (INK4a) is an early event in lung cancer and a potential biomarker for early diagnosis. Proc Natl Acad Sci USA 95: 11891-11896, 1998.

31. Nuovo GJ, Plaia TW, Belinsky SA, Baylin SB and Herman JG: In situ detection of the hypermethylation-induced inactivation of the p16 gene as an early event in oncogenesis. Proc Natl Acad Sci USA 96: 12754-12759, 1999

32. Guzman LM, Koriyama C, Akiba S, et al: High frequency of p16 promoter methylation in non-small cell lung carcinomas from Chile. Biol Res 40: 365-372, 2007.

33. Ko E, Kim Y, Lee BB, et al: Relationship of phospho-pRb (Ser-807/811) level to exposure to tobacco smoke in primary non-small cell lung cancer. Cancer Lett 274: 225-232, 2009.

34. Liu Y, Lan Q, Siegfried JM, Luketich JD and Keohavong P: Aberrant promoter methylation of p16 and MGMT genes in lung tumours from smoking and never-smoking lung cancer patients. Neoplasia 8: 46-51, 2006.

35. Kawano Y and Kypta R: Secreted antagonists of the Wnt signalling pathway. J Cell Sci 116: 2627-2634, 2003.

36. Mazieres J, He B, You L, et al: Wnt inhibitory factor-1 is silenced by promoter hypermethylation in human lung cancer. Cancer Res 64: 4717-4720, 2004.

37. Karpf AR and Jones DA: Reactivating the expression of methylation silenced genes in human cancer. Oncogene 21: 5496-5503, 2002. 